\title{
LOS JURISTAS FRENTE A LA SOCIEDAD (1975-1993)
}

\author{
«Las tragedias de los otros son siempre de una banalidad \\ desesperante». \\ Oscar Wilde, Retrato de Dorian Gray, Cap. 4.
}

\section{Veinte años después}

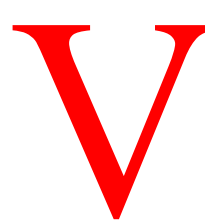

einte años han pasado desde la publicación en Francia de la obra Les juristes face à la société ${ }^{1}$. Mis colegas todavía no han digerido, creo, el hecho de que uno de ellos haya osado hablar de una confrontación entre los juristas y la sociedad. Eso no existe... o no se dice. Y sin embargo, esta crisis del Derecho, de las instituciones y de la justicia llena -aunque sólo sea en el apartado de «sucesos»- las páginas de los periódicos. Las pantallas de nuestras televisiones dan testimonio de ello todos los días. No son más que gritos de alarma acerca de la incomprensión de nuestros gobiernos hacia la justicia, la incomprensión de la justicia hacia los justiciables, la incomprensión por parte de las «autoridades» hacia las necesidades de la calle.

Que yo sepa, el cara a cara mismo no ha envejecido, aunque las últimas páginas del libro han comenzado -no lo discuto- a tener arrugas. O quizá sería más exacto decir que están «anticuadas». Nada de lo que hay en él es falso. Pero si lo retomo desde un punto de vista antropológico, me doy cuenta de que tales páginas son más la autopsia de un jurista intelectual de izquierdas ${ }^{2}$ que ha vivido este periodo, que una estricta relación histórica. El juicio más acertado será el que refleje el exceso de subjetividad que se aprecia en la conclusión.

${ }^{1}$ André-Jean Arnaud, «Les juristes face à la société», Presses Universitaires de France, 1973.

${ }^{2}$ Me permitiré aquí la libertad de utilizar el sin sentido «jurista intelectual» que además, unido al calificativo «de izquierdas», se muestra menos paradójico que una utopía que en ocasiones llegara a realizarse. Yo no permito a mis colegas ni que me tachen de no ser jurista, ni que me nieguen una sensibilidad de izquierdas. Todo lo más que podrán decir, no sin razón, es que no soy un intelectual. 
Veinte años, por tanto, han pasado con su cortejo de entusiasmos y desilusiones; también con la experiencia y quizá la sabiduría que aportan, junto con la edad, el tiempo dedicado a la investigación y a la acción, y las largas veladas consagradas al estudio y a la meditación. Que el lector no espere aquí, sin embargo, el libro que merecería esta mirada al pasado ${ }^{3}$. Me limitaré a hacer algunas reflexiones fundadas en textos de los cuales unos, la mayoría, han sido ya ofrecidos al público, y otros lo serán próximamente ${ }^{4}$.

Hemos sido testigos de enormes y radicales cambios. Desde hace ya un cuarto de siglo, como ya he escrito en algún otro lugar ${ }^{5}$, vivimos con agitación la descomposición de los grandes sistemas teóricos: los marxismos, los estructuralismos, y los funcionalismos. Vemos desenvolverse pensamientos de tipo interaccionista; valoramos no sin ansiedad la comunicación, el intercambio, la idea de red; nos interesamos más por el cambio que por el orden, por las rupturas que por la tranquilizante permanencia; somos sensibles a la complejidad, al pluralismo, a la suavidad, a la flexibilidad, a la ligereza...

Por lo que se refiere al Derecho, nosotros, juristas diferentes, nos damos cuenta de que los tiempos que corren necesitan nuevos modelos. Hemos tenido ya suficientes ilusiones de modernidad. Basta ya de la ilusión del progreso ininterrumpido y programado; basta ya de la simplicidad y del rigor de la razón; basta ya del universalismo que, diluyendo el pasado y un futuro sin riesgos en un presente perpetuo, nos priva del ejercicio de nuestra voluntad en la elección de nuestro porvenir; basta ya, en fin, de ideologías normalizadoras que nos presentan la modernidad como un sistema cerrado, cultivando lo ineluctable y lo irreversible como razones para someterse a la norma.

No somos los únicos que vivimos esos conflictos. La sociedad contemporánea nos ofrece el espectáculo de reacciones a veces incontroladas que van desde los neomodernismos hasta los neofundamentalismos. Huyendo del desarraigo, de la soledad existencial, de la confusión axiológica, del desconcierto social, algunos, cada

\footnotetext{
${ }^{3}$ La dificultad del género me ha llevado a solicitar las observaciones de Wanda Capeller, Jacques Commaille y François Ost, en los que he podido apreciar, una vez más, el rigor y la amistad. Las líneas que siguen son deudoras de los debates suscitados por una versión inicial de este texto. Les quedo profundamente agradecido.

${ }^{4} \mathrm{Me}$ citaré abundantemente en estas notas: no se trata de autosuficiencia, sino de voluntad de no cargar demasiado estas notas por desarrollos que se encontrarán fácilmente en otras partes y de deseo de compartir con el lector una evolución intelectual de dos décadas -si mis preocupaciones, en el fondo, no han cambiado, al menos se puede esperar que mi experiencia se haya visto enriquecida.

${ }^{5}$ «L'avvocato fra modernismo e post-modernismo», en Rivista trimestrale di Diritto e Procedura Civile, XLV/4, 1991, págs. 1229-1236.
} 
vez más numerosos, se refugian en el narcisismo de lo privado, en lo irracional, en el integrismo religioso, en la violencia o en la droga. El Derecho ya no puede hacer nada más por ellos, ni siquiera contra ellos para una eventual protección de la sociedad, pues las medidas de coacción no son apropiadas contra la miseria moral o física-, y si continúan así las cosas por mucho más tiempo, pronto la mayor parte de la población caerá bajo el peso de la ley, y la conformidad con la norma será la excepción y el incumplimiento lo general.

En pocas palabras, el carácter específico de este fin de siglo no será tanto el haber sido el de la duda, el del escepticismo y el de la paradoja, sino sobre todo el hecho de haber transcurrido en la tristeza, la amargura, la morosidad y el mal humor. Y es que las paradojas, bien mirado, son una forma de progresar. Y desde este punto de vista las instituciones, el Derecho y la justicia -y, por lo tanto, los juristas- podrán resultar engrandecidos. Sólo necesitarán dedicarse a velar por la permanencia de los viejos mitos, especialmente el de los condenados del Tártaro, el del talón de Aquiles y el de Ulises y las sirenas.

\section{Los condenados del Tártaro}

La Odisea nos cuenta que, en esta región de los infiernos, donde los culpables expían eternamente tras su muerte las faltas cometidas durante su existencia terrenal, se encontraban tres condenados: Titón, Sísifo y Tántalo.

El castigo del primero -uno de los Gigantes, hijo de la tierra, padre de Europa ${ }^{6}$ consistía en que dos buitres devoraban su hígado mientras éste crecía ininterrumpidamente. Sísifo sostenía con sus dos manos una piedra enorme y la hacía rodar con esfuerzo hacia la cumbre de una colina, pero una fuerza poderosa la repelía haciéndola caer hacia el fondo, debiendo recomenzar su tarea. Por último Tántalo, sumergido hasta el mentón en un lago, no conseguía ni beber ni alcanzar los frutos que colgaban de los árboles por encima de su cabeza, ya que el agua se apartaba cada vez que él acercaba los labios y el viento echaba hacia atrás las ramas de los árboles cuando él levantaba la mano. La imposibilidad de alcanzar un fin aparentemente visible, labor sin fin, enfermedad permanente: tales son los males que sufre el jurista contemporáneo. ¿Pero con qué derecho había creído este último poder escapar a su condición humana?

${ }^{6}$ Una Europa diferente a la que era hermana de Cadmos (cf. las explicaciones suministradas en Pour une pensée juridique européenne, PUF, París. 1991, pág. 35). 
Habiendo pasado, no hacía mucho, «de los manuscritos al ordenador» ${ }^{7}$, viendo cómo se abrían sendas de reyes por el progreso insospechado de la técnica, de la tecnología, de la electrónica, y a la vista de las esperanzas que habían alimentado sus perspectivas, su decepción no podía ser otra: inmensa. Al final de este siglo operarán dos constantes: que nunca se puede hablar del Derecho cómo de algo concluido y que toda regulación jurídica está, por naturaleza, en permanente renovación.

\section{A) Un Derecho nunca concluido}

Las décadas precedentes conocieron el apogeo de los códigos. El fenómeno se prolongó, desarrollándose a causa especialmente de una ofensiva de la jurisprudencia, de una internacionalización de los debates jurídicos y de un renacimiento del pluralismo normativo.

Para comenzar encontramos el asedio, si no el asalto, de la jurisprudencia. A través, especialmente, del Derecho comunitario y del Derecho europeo, donde los tribunales de Luxemburgo y de Estrasburgo desempeñan un papel dominante, los Derechos nacionales poco a poco -y cada año más- reciben jurisprudencia. Los tribunales de orden interno juegan un papel creciente por la integración, dentro de su propia jurisprudencia, de la jurisprudencia europea. Recuperan, por este hecho, un papel creativo para el que nuestros magistrados, formados todavía según la tradición continental, no estaban preparados.

Por consiguiente, las bases de datos jurisprudenciales (y jurídicos de manera general) que habían conocido ya un auge importante antes de 1975, adquieren una importancia considerable. En Francia, donde todo abonado a una línea de teléfonos puede beneficiarse de una pequeña terminal llamada «Minitel», un gran número de estas bases de datos son accesibles con el simple abono. Digo bien: no sólo los profesionales, sino también los particulares. En la práctica, evidentemente, esto no significa que el hombre de la calle consulte a diario la jurisprudencia, pero quiere decir que el conocimiento jurídico está hoy en día al alcance, por ejemplo, de las asociaciones de defensa de intereses, por modestas que éstas sean.

La jurisprudencia no es la única que contribuye a la sobre-saturación de nuestros códigos; hay que contar también con la inflación legislativa y reglamentaria, una verdadera «legorrea». La apertura de Europa contribuye, por supuesto, a precipitar las cosas, especialmente

${ }^{7}$ La expresión constituye, recordemos, uno de los subtítulos de la Conclusión que precede. 
por lo que se refiere a la reglamentación. Pero no es el único factor. Un balance de la última legislatura en Francia, al comienzo de las elecciones de marzo de 1993 en la Asamblea Nacional, muestra una excepcional recuperación de la actividad legislativa a pesar de la muy exigente Constitución de la V República: 455 leyes en cuatro años, esto es, una ley cada dos o tres días hábiles.

A este paso se admitirá que el Derecho, según la definición que del mismo nos enseñan como conjunto de reglas que delimitan lo justo y que por su constancia asegura la seguridad y el bienestar de los individuos, no es nunca, en realidad, algo concluido.

Se esperaba, sin embargo, mucho de una internacionalización de la vida intelectual. Sociólogos juristas, filósofos y teóricos del Derecho, politólogos, internacionalistas, especialistas del Derecho comunitario y del Derecho europeo, expertos en nuevas tecnologías, se reúnen cada vez con más frecuencia, mundializan sus debates, intercambian problemas y fórmulas. Los sociólogos han creado incluso un Instituto Internacional de Sociología del Derecho ${ }^{8}$, mientras que los teóricos del Derecho han puesto en funcionamiento una Academia Europea de Teoría del Derecho ${ }^{9}$. Todos son conscientes del fenómeno de globalización de la economía y, en consecuencia, de la globalización de las relaciones jurídicas destinadas a regular las relaciones económicas. Hablamos mucho de la CEE. Pero ¿quién sabe en nuestro viejo continente que los Estados Unidos, Canadá y México han concluido igualmente un tratado de libre comercio que plantea cuestiones bastante similares a las que surgen aquí en Europa?

Todos son conscientes de que el ordenamiento jurídico no puede seguir siendo concebido en términos nacionales, ni siquiera internacionales (que viene a ser casi lo mismo en la medida en que el orden internacional reenvía, por definición, al nacional). Así, la «comunidad» es presentada por los juristas del Derecho comunitario como una instancia sui generis, ni nacional, ni internacional. Otro ejemplo es el proporcionado por las investigaciones sociológicas recientes acerca de la cultura jurídica: algunos sociólogos tienen en cuenta eso que ellos llaman «terceras culturas» cuyo rasgo característico consistiría precisamente en su desarrollo autónomo. Estas permitirían dar cuenta de las interacciones jurídicas que desafían a las normas elaboradas a la manera tradicional, implementadas y garantizadas por las instituciones que operan en el marco conceptual del Estado-Nación. Esta noción permitiría explicar -la descripción constituye

\footnotetext{
${ }^{8}$ Instituto Internacional de Sociología del Derecho IISL), Antigua Universidad, A.P. 28, E-20560 OÑATI, Guipuzkoa, España.

${ }^{9}$ F.U.S.L.. Bld du Jardin Botanique 43, B-1000 BRUXELLES, y K.U.B.
} 
un primer paso hacia la predicción- numerosos fenómenos difíciles de aprehender con los conceptos y técnicas de nuestro tiempo y para cuyo tratamiento el Estado se confiesa incapaz $^{10}$.

Finalmente, no hay que olvidar que el Derecho se vuelve cada día más incierto en un periodo en el que la unificación europea lleva aparejada la noción de pluralismo; noción que, desde el siglo XVI, había intentado ser desplazada, lenta pero certeramente, en los Derechos nacionales. Se trata de un doble pluralismo jurídico y cultural. El pluralismo jurídico es evidente. El Derecho europeo -que es a partir de ahora el nuestro- es un monstruo compuesto por el Derecho de las Comunidades Europeas, el Derecho de las organizaciones internacionales, el Derecho de las naciones que forman parte de Europa, y por los Derechos surgidos de las relaciones internacionales entre uno de los Derechos citados y el de otro Estado o el de otra comunidad $u$ otro ordenamiento comunitario, internacional o supranacional. Acaba de incorporarse un pluralismo cultural, aunque sólo sea por el hecho de que cada uno de estos Derechos se basa en fundamentos culturales específicos. Pero, al hablar de pluralismo jurídico, hay que tener en cuenta, igualmente, la intervención de una nueva definición de la cultura jurídica que ha surgido en los años 1980 y que ha ido imponiéndose progresivamente por la pluma de los sociólogos juristas. Esta noción permite vislumbrar -lo cual no simplifica las cosas la posibilidad de un Derecho en permanente cambio.

\section{B) Un Derecho en permanente cambio}

Hablábamos de mitología. Es a Fénix a quien podríamos ahora aludir. Y, sin embargo, no es exactamente de sus cenizas de donde nace el Derecho. Aunque este último esté en un perpetuo renacer, no se trata de una resurrección. Los factores de cambio han estado siempre presentes: eran los juristas los que no eran conscientes, mientras que los sociólogos y los antropólogos no paraban de ofrecerles ejemplos. Estos trabajos, es cierto, pertenecen en su mayoría a la literatura anglosajona y americana que, desgraciadamente, con frecuencia nuestros colegas continentales no tienen tiempo de leer.

Por «cultura» ya no se entiende sólo el conjunto de valores, principios e ideologías relativas al Derecho, ni el conjunto de técnicas de exposición y de interpretación empleados por los operadores jurídicos, ni el conjunto de opiniones y de apreciaciones del público acerca del Derecho y de la justicia. Se trata ahora de un concepto igualmente

${ }^{10}$ Objeto del curso de Master de la IISL (citado supra nota 6) a partir del curso universitario 1993/94. 
utilizado cuando deseamos explicar las diferencias nacionales y locales en el pensamiento o en la práctica jurídica, sin saber con precisión cuáles pueden ser los factores que los expliquen ${ }^{11}$.

Ahora bien, la «cultura jurídica» tal como aparece en los años 80 toma en cuenta elementos que se desarrollan especialmente bajo el impulso de los hechos económicos, de los cambios operados en la sociedad, de todo tipo de polémicas, de la mediatización del suceso más pequeño, de la transformación de las costumbres, de la desnaturalización de los motivos de insatisfacción de los administrados en supuestos debates públicos. Asistimos a un increíble auge de las formas alternativas de resolución de conflictos ${ }^{12}$; observamos el creciente papel de los profesionales del Derecho ${ }^{13}$; somos testigos de la reivindicación de una participación, cada vez mayor, de lo «local» en la decisión. Este punto es el que se nos presenta probablemente como la mayor novedad -al menos por lo que se refiere a Francia, de larga tradición jacobina. Pero también podría interesar mucho a otros países de la comunidad, ya que esta toma en consideración de lo «local» rompe incluso con los usos regionales o federales. En la época del resurgimiento de las «Ligas», nuestros amigos italianos no serán insensibles al debate.

Novedad, en efecto, pues el problema es enfocado de una forma hasta ahora inédita. Hasta entonces la novedad de las reivindicaciones de participación para la preparación de las decisiones (jurídicas) estaba en el hecho de que ellas emanaban de grupos de presión, especialmente de lo que se denominaban las «minorías»: mujeres, ecologistas, presos, menores, enfermos mentales, soldados, homosexuales... Estos grupos se integraron rápidamente en la vida política, salvo cuando habían pura y simplemente desaparecido de la escena. A partir de ahora la reivindicación «local» responde a un estallido de las soberanías nacionales. La filosofía «moderna» del Estado y del Derecho nos decía que toda soberanía emanaba única y exclusivamente del Estado-nación. Ahora bien, cada día vemos ante nuestros ojos cómo se desmorona esta verdad. Desde el momento en que un país por si sólo no puede hacer frente a las especulaciones con su

${ }^{11}$ Ver voz «Cultura» (especialmente el apartado 6) en la nueva edición, 1993, del Dictionnaire encyclopédique de théorie et de sociologie du droit, L.G.D.J., París.

${ }^{12}$ Ver voz «Alternativo (Derecho-): Alternativa (Justicia-)» en la nueva edición, 1993, del Dictionnaire encyclopédique de théorie et de sociologie du droit, op.cit.

${ }^{13}$ Además de los numerosos estudios consagrados a este tema, ¿quién de entre nosotros no se ha preocupado, por ejemplo, de la creciente sofisticación de los mecanismos de control social, aunque sólo sea por el abuso que hace nuestro sistema jurídico y judicial del recurso a los expertos? 
moneda, no se puede decir que la economía pertenezca verdaderamente a los Estados-naciones; las multinacionales son hoy en día la regla general, en los aspectos más importantes de los asuntos económicos intervienen las comunidades de Estados. Lo único que les queda a las naciones es el poder -también restringido- de corregir, a través de medidas de orden interno, los grandes daños que causan a su propio sistema las decisiones internacionales y los sucesos económicos mundiales.

Junto a este movimiento -que irá ampliándose- de deslocalización de los poderes de decisión jurídica, hay que añadir, correlativamente, el debate en torno al papel de los tecnócratas. En primer lugar, la burocracia de Bruselas (obsérvese la sucesión de noes y de casi noes -un sí muy poco aventajado en votos- en el tratado de Maastricht); pero todo esto se aplica también a las tecnocracias gubernamentales (así, por ejemplo, el papel creciente de los verdes contra vanas decisiones tomadas en los «despachos» de los ministerios y de las administraciones).

\section{El talón de Aquiles}

Todo lo anterior da lugar a que nosotros los juristas manejemos un Derecho frágil. Delicado, incierto, provisional, cambiante, inconstante; el Derecho es todo ello a causa de sus paradojas internas, a causa de la precariedad de su objeto, y a causa de la incertidumbre actual que reina sobre sus fundamentos epistemológicos.

\section{A) Las paradojas del Derecho.}

El Derecho contemporáneo aprende, a su pesar, a dirigir la complejidad del mundo en cuyo seno se inscribe. Pero, en las mismas tentativas de cambio, observa cómo nacen las paradojas. Señalaré aquí las ocho de mayor importancia ${ }^{14}$.

Primera paradoja: lo universal y lo particular. Mientras que nuestros Derechos han sido cuidadosamente elaborados sobre fundamentos universalistas, individualistas y subjetivistas, que han permitido la elaboración del concepto protector de derechos humanos, ya la idea de relatividad de las culturas nos recuerda que lo que es considerado

\footnotetext{
${ }^{14}$ Las reflexiones que siguen -que he madurado gracias a cursos y conferencias, con la ayuda de mis interlocutores- serán objeto próximamente de una publicación cuyo título evocará las paradojas de un Derecho postmoderno.
} 
aquí como seguridad de las personas es, allá, una violación a los principios fundamentales. Incluso entre nosotros sufrimos hoy el exceso con el que han sido desarrollados los derechos del individuo en las cartas «sociales», elevando por ejemplo a la calidad de derechos humanos, inviolables y sagrados, el trabajo y la salud. ¡Como si el trabajo pudiera ser garantizado para todos en una economía que ha llegado a ser planetaria! ¡Como si existiera un derecho inherente al individuo a nacer con «salud»! En realidad libertad/igualdad, trabajo y salud no pertenecen a la misma «clase» de derechos humanos. Pero nuestra práctica jurídica todavía no ha asimilado estas sutiles distinciones de la teoría. ¿Acaso es capaz de hacerlo? Hasta que eso suceda, deberemos vivir con esa paradoja de lo universal como fundamento de nuestras democracias -incluyendo eso que se ha denominado la sobre-ideologización de los derechos humanos ${ }^{15}$ - y de lo relativo como fundamento de nuestra práctica jurídica. Es el fin del mito del Derecho universalmente válido y protector, cuyas premisas continúan sin embargo acunando los sueños de nuestras democracias -que a pesar de todo son (hasta que los hechos, con el tiempo, demuestren lo contrario) el menos malo de los sistemas políticos contemporáneos.

Segunda paradoja: la re-regulación y la desregulación. A fin de servir a los intereses del liberalismo económico, nuestros juristas y políticos se han lanzado a cuerpo descubierto a la demostración de los beneficios de la desregulación. Ahora bien, al mismo tiempo, asistimos a una demanda cada vez más fuerte de re-regulación: problemas de sangre contaminada en Francia y, de rebote, en otros países (¿por que no estaba esto reglamentado por los Estados cuando era tan peligroso?); peticiones para una regulación en materia de bioética (nuestras sociedades se revelan incapaces de regirse por la ética y acuden al Derecho; al cual, por otra parte, no cesan de condenar en nombre del excesivo intervencionismo por parte del Estado)... Podrían darse múltiples ejemplos. Es éste un nuevo tipo de «juridicismo», que no es más, esta vez, que la obra de juristas inclinados a ver Derecho por todas partes, y a no reconocer ningún otro modo de regulación que no sea el realizado por medio del Derecho. Es un tipo de «juridicismo» vulgar o populista, como se quiera, en el que están todos dispuestos a quejarse de cualquier «vacío» que se descubra en la regulación estatal a fin de beneficiarse al máximo de la incubadora social en la cual, desde hace unas décadas, nacemos todos.

\footnotetext{
${ }^{15}$ Gérard Soulier, «Ingérence ou assistance humanitaire. Évolution des principes humanitaires», en Psychanlystes, 45, 1993.
} 
Tercera paradoja: los beneficios y los perjuicios de la regulación social utilizada en las relaciones jurídicas. La aparición de alternativas (jurídicas) al Derecho del Estado corre el riesgo de tener efectos perversos. En lugar de suavizar las relaciones en el seno de la sociedad civil, en algunas ocasiones estas alternativas garantizan un reforzamiento del control del Estado ${ }^{16} \mathrm{y}$, en otras, son los más desvalidos los que pagan las consecuencias ${ }^{17}$.

Cuarta paradoja: la igualdad entre sujetos de Derecho en una sociedad plural. Se trata de la aparición -concomitante con la exigencia de más justicia, más igualdad, más participación de los ciudadanos en la vida social- junto a estos sistemas alternativos de regulación jurídica o de resolución de conflictos, de una sociedad plural que comporta dos subsistemas que se autorregulan. Sería aceptable una cierta dosis o un cierto tipo de pluralismo que permitiera luchar contra la hegemonía del Derecho estatal; pero no que introdujese en el cuerpo social diferencias que un Derecho de emanación única (el Estado como poder delegado de los ciudadanos) pudiera nivelar: ¿Debemos aceptar sin movernos tal retroceso? Hay que estar alerta.

Quinta paradoja: el amor/odio del censor. Por retomar la bella idea de Pierre Legendre ${ }^{18}$; también la podríamos denominar la paradoja de la marginación y del retorno del juez. Mientras que la sociedad busca vías alternativas, soluciones pluralistas a sus problemas jurídicos, se observa un retorno a la judicatura. Los magistrados del orden jurídico ya no pueden contentarse con ser la boca de la ley. Deben encontrar, junto a los otros participantes e interlocutores sociales, soluciones pragmáticas -a veces en el límite del poder que les otorga su función, lo que prueba su valentía y desinterés- a los asuntos que les son sometidos. La intervención del juez delegado (a menudo establecido en la ley) se hace cada día más frecuente. Más allá de los dossiers que tiene que abrir, el juez se convierte cada vez más en el responsable de la protección y de la educación de los individuos que le son encomendados. Además actualmente el juez está asociado, en numerosos casos, a la ejecución de las sentencias. ¡Crisis de la Justicia! ¿No es un poco apresurado?... A menos que se

\footnotetext{
${ }^{16}$ Ver Stanley Cohen, Visions of social control, Polity Press, Cambridge, 1985; Dario Melossi, The State of Social Control, Polity press, Cambridge, 1990.

${ }^{17}$ Ilegalización en Japón, por una ley de 1 de marzo de 1992, de tres asociaciones de gangsters que, con toda legalidad, por medio de intervenciones alternativas en la mediación de conflictos judiciales, transacciones inmobiliarias y reembolso de deudas, timaban a sus clientes.

${ }^{18}$ Pierre Legendre, L'amour du censeur, Le Seuil, París, 1974.
} 
entienda por tal que los jueces ya no saben exactamente cómo «hacer frente» (que es lo contrario de estar cara a cara) a estos múltiples requerimientos, con los límites de las fuerzas humanas.

Sexta paradoja: lo nacional y lo local. Cuando se desarrolla lo local, ¿no se corre el riesgo de caer en callejones sin salida, de asistir a retrocesos? ¿Cuántos poderes locales no estarán tentados por la idea de proteger a su restringida comunidad contra los extranjeros? La exclusión del Otro, para cuya reducción, en la práctica y en las mentalidades, nuestros Derechos «modernos» -por muy polvorientos que estén con el paso de los años- han empleado tanto tiempo.

Séptima paradoja: la necesaria e imposible gestión de la complejidad ${ }^{19}$. La consideración de la complejidad, que implica -para su funcionamiento- la recurrencia entre los niveles previamente descubiertos, corre gran riesgo de convertirse en una espiral infernal. Si admitimos que nuestras sociedades son complejas y que el medio ambiente no está constituido por subsistemas independientes entre sí, sino que, al contrario, todo esto no son más que cosas recurrentes y bucles extraños ${ }^{20}$, ¿debemos preguntarnos dónde se pararán los unos y los otros? ¿dónde, cuándo y según qué modalidades podrá intervenir la decisión jurídica que, sin molestar a nadie, implicará una participación de todos y revestirá el doble carácter de decisión para la acción y de medida de satisfacción ${ }^{21}$ ?

Octava paradoja: finalmente, la paradoja de las paradojas: ¿cómo vivir todas estas paradojas sin deshacerse en la paradoja? La reflexión en términos de paradojas ¿no da lugar a un bloqueo de la actividad? Y el arte jurídico ¿no consiste en tratar lo complejo como si no lo fuera? Prohibiéndose reducir la complejidad, ¿no se corre el riesgo de conducir este arte a su fin? El Derecho, tal como nosotros lo conocemos y lo practicamos, no está preparado para dirigir una sociedad postmoderna. Ha sido denunciado por ser la forma de regulación por excelencia de una paz burguesa ${ }^{22}$; pero todavía no hemos encontrado las llaves de un Derecho fundado en premisas cuya validez

${ }^{19} \mathrm{Cf}$. André-Jean Arnaud, «Reflexions on «complex decision» and European law-making process», en On Complexity and Socio-Legal Studies, Oñati IISL, 1993 (Oñati Proccedings, vol. 14).

${ }^{20}$ Ver Michel Van de Kerchove y François Ost, Le système juridique entre ordre et désordre, P.U.F., París, 1988.

${ }^{21}$ Cf. André-Jean Arnaud, «Vers un processus de décision complexe en Droit», en Lire le droit: langue, texte et cognition, bajo la dirección de D. Bourcier y E. MacKay, Paris, L.G.D.J., 1992 (coll. «Droit et Société», vol. 3). especialmente pág. 80.

${ }^{22}$ Reenvío aquí, por supuesto, a mis trabajos precedentes sobre esta materia, entre ellos al artículo publicado en los Quaderni fiorentini per la storia del pensiero giuridico moderno, Milano, Guiffrè, 1973: 147-176. 
no esté ampliamente superada. Todo lo más nos obstinamos en forzar la cerradura para abrir la puerta que nos separa de esta sociedad que ha entrado en la presente época y que permanece, por ello, extraña al Derecho que la rige.

Los sucesos internacionales que tenemos ante nuestros ojos, este tipo de intervenciones semiarmadas ${ }^{23}$ autorizadas por un Derecho supra-nacional promulgado de hecho por algunos Gobiernos, tienen una naturaleza espuria que revela perfectamente estas paradojas con las que tenemos que convivir: ayuda humanitaria, pero que por otra parte se asemeja mucho a una suerte de «cruzada» ${ }^{24}$. Aquellos de nuestros descendientes que analicen la época contemporánea, ¿no correrán el riesgo de ver en esto sólo un episodio más de la larga historia de las empresas de «pacificación», de las luchas de las civilizaciones por su preeminencia o por su supervivencia?, ¿dónde está el Derecho?, ¿dónde está la justicia? Quizá aquí se pueda, fácilmente, llegar a las causas reales de la crisis del Derecho y de la justicia que a nivel nacional se atenúan, ocultando así el mal.

\section{B) La fragilidad del objeto}

El objeto denominado Derecho se multiplica. Aquí no evoco tanto nuevos campos de estudio y de práctica (el Derecho comunitario, el Derecho europeo, la multitud de Derechos de las nuevas tecnologías), como la extensión de la regulación social por la producción de normas (jurídicas) no gubernamentales. Para el jurista y para el sociólogo el objeto «Derecho», que ya no era el mismo, no cesa de cambiar.

Vemos dibujarse una tendencia: los cursos de Derecho tradicional siguen siendo patrimonio exclusivo de las Facultades de Derecho, mientras que el estudio del Derecho en acción se hará al margen, en grupos de investigación sobre el Derecho y la sociedad, en los círculos de crítica del Derecho, en los nuevos caminos explorados

${ }^{23}$ Se me permitirá el término: nuestros contemporáneos hablan de «iguerra limpia!». Pero todos esos Estados que se conducen como gendarmes del mundo, por más que pinten a sus soldados el casco de azul y a sus carros de combate de blanco, ¿quién va a creer que no tienen intereses mayores en las intervenciones que evalúan y seleccionan con tanto cuidado?

${ }^{24}$ Releeremos sin cansarnos la tesis doctoral que Michel Villey ha publicado bajo el título: $\mathrm{La}$ Croisade. Essoi sur la formation d'une théorie juridique, Vrin, Paris. 1942. 
por los más destacados sociólogos juristas contemporáneos, que en la mayoría de las ocasiones tienen poco que ver con la tradicional sociología del Derecho tal como es enseñada, cuando lo es...

En pocas palabras, se presiente, a partir de todo lo anterior, que el objeto del Derecho es una de las causas de las enfermedades que padecen nuestros juristas. Es cierto que es una materia que requiere un alto nivel de tecnicidad. No hay experiencia ni prueba posible en este campo. Todo asunto concierne a personas que sufren y a cuestiones vitales: una decisión es -si se revela nefasta- irreparable en sentido estricto.

Los juristas deben entonces ser buenos técnicos. Y por esa razón deben apoyarse sobre un saber sólido. Ahora bien, el conocimiento, como en toda materia, se basa en categorías; y uno de los grandes problemas que plantea el Derecho es que las categorías jurídicas desafían toda relación con otras disciplinas. En esto se encuentra la especifidad fundamental del Derecho. Aquí reposa la animadversión tradicional entre los juristas y los investigadores de las ciencias sociales.

Si tornamos en cuenta ahora la indigencia cultural que se notaba ya desde antes de 1975 en los programas de las Facultades de Derecho, no sólo encontramos una explicación a este abandono de las materias no técnicas, sino que también podemos tratar de hacer pronósticos. ¿Vamos a seguir llorando durante mucho tiempo la desaparición de la Universidad en tanto que universitas, patrimonio común de los intelectuales, lugar donde las disciplinas tienen su punto de encuentro? Lágrimas de cocodrilo. De la Universidad ha desaparecido sobre todo la imagen de Epinal. Y la cultura no habría abandonado las Facultades de Derecho si los juristas no hubieran permanecido impasibles frente a [retomo aquí la idea de mi cara a cara] las nuevas formas de cultura jurídica, si no se hubieran empeñado en considerar en su formación únicamente los elementos técnicos al uso en el Palacio de justicia, en las administraciones o en las empresas, ignorando todo lo «jurídico» que, sordo en los intersticios del Derecho oficial ${ }^{25}$, frecuentemente fluye como un río tranquilo al margen del Derecho del Estado y a veces brama como un torrente cuando el cauce se desborda.

La cultura, a partir de esta nueva definición, puede entonces entrar a formar parte de las Facultades de Derecho. Pero no hay que ocultar que esto tendrá lugar sobre el background «cultural» de cada

${ }^{25}$ Sobre la necesaria distinción entre el Derecho y lo jurídico, ver, además de mi estudio Critique de la raison juridique: I -Où va la sociologie du droit, L.G.D.J., París, 1981, mi estudio sobre «Rossinante et le cheval de Troie: Juridicité et raison juridique au crible de la rande dichotomic», en Procès, 
nación (en el sentido más tradicional de la palabra «cultura»), pues es ahí donde se continúa ofreciendo la formación jurídica. La consecuencia es clara: a la división de los juristas, atendiendo a que su formación repose en las manos de los corporativistas, de los tecnócratas o de los investigadores de las ciencias sociales, vendrá a superponerse una división atendiendo a las distintas culturas jurídicas. Se corre el riesgo de que se acentúe la diferencia Norte y Sur.

He aquí lo que hace más frágil todavía al Derecho y a los juristas. En la época de las Comunidades Europeas, en la época del gran enfrentamiento con los colosos del otro lado del canal de la Mancha, los juristas y los despachos de abogados continentales aún no están preparados para afrontar la competencia ${ }^{26}$. Se dirá que, en este debate, no tienen por qué preocuparse por su formación cultural. Falso: los americanos y los anglosajones de manera generalizada tienen culturalmente lazos profundos y permanentes con toda la tradición «jurídica» que nosotros, ligados a una tradición romano-canónica, no reconocemos como Derecho. Y es por esto que están preparados culturalmente para las grandes revueltas de la práctica jurídica que sufrimos y que van a aumentar todavía más.

No es que tengamos que inclinarnos agradecidos ante todo lo que nos venga del extranjero y que nos parece tener más éxito que nuestras empresas. Como repetía el decano Carbonnier: De luengas tierras, luengas mentiras... Pero esto podría llevarnos a iniciar un examen de conciencia. Y para comenzar, ¿nuestras incertidumbres no provienen de lo más recóndito de la filosofía jurídica? ¿No dependen de los fundamentos epistemológicos de nuestros Derechos?

El porvenir bien podría abrirse ante los que aceptaron no obnubilarse sobre el objeto «Derecho», sino trabajar en términos de «proyecto». En otras palabras, abandonar el viejo esquema positivista normativista que está fuera de uso, para adoptar los contornos de las epistemologías constitutivas ${ }^{27}$. Si se acepta particularmente que en

1982/9: 75-88 [en inglés: «Fact as Law» en Semiotics, Law and social Science, B. S. Jackson y D. Carzo ed., Roma-Liverpool, Gangemi-Liverpool Law review, 1985: 129-144; en español: "Algunas reflexiones sobre las relaciones entre la filosofía del derecho y la crítica jurídica», Cuadernos de Trabajo de la IFD/LUZ, Maracaibo, 1984 (n. ${ }^{\circ} 38$ ); en alemán: «Der Begriff der juristische Ratio als Mittel zur Überwindung der Gegensatzes zsvischen Sein und Sollen»; en portugués: «O conceito de razao jurídica como maneira de ultrapassar a oposiçao tradicional entre o ser e o dever ser», en Contradogmáticas, 4/5, 1985: 21-361.

${ }^{26} \mathrm{Cfr}$. Batailles territoriales et querelles de cousinage: juristes et comptables européens sur le marché du droit des affaires, bajo la dirección de Yves Dezalay, Paris L.G.D.J., 1993 (Coll. «Droit er Société», vol. 7). 
materia científica nada está dado sino que todo es construido, entonces importará menos el objeto (sobre el cual juristas y teóricos de otras disciplinas interesados en el Derecho y la justicia no pueden fijar sus límites ${ }^{28}$ ) que el proyecto. Ya no será imposible construir, sobre esta base así renovada, una interdisciplinariedad que es cada día más necesaria en las relaciones jurídicas, y que al jurista por sí sólo le cuesta dominar cada vez más.

Pero no hay que ocultar tampoco que estos conceptos son aún inciertos, se encuentran en fase de investigación; los prácticos están invitados a colaborar con su propia experiencia en una búsqueda en la que los intelectuales aislados estarían desvalidos. Sólo de la dialéctica entre pensamiento y acción surgirán los fundamentos filosóficos del Derecho del futuro. La interdisciplinariedad no consiste en renegar de la especialización, en exaltar al simple aficionado frente al profesional. Se trata de permitir dialogar, a los especialistas de las diversas disciplinas implicadas en el ámbito del Derecho y de la justicia, sobre algo más que un objeto nunca compartido.

\section{Ulises y las sirenas}

Quienquiera que sea, no debe dejarse llevar ni por la derrota ni por el canto de las sirenas, tan numerosas como los falsos profetas, como los inspirados poetas que nos anunciaban sus apocalípticos fines de milenio.

\section{A) El descrédito de los jueces}

Vanidad de vanidades, y todo es vanidad, nos recordaba Bossuet. La naturaleza humana olvida rápidamente la advertencia, y nadie está al amparo de las ridículas e irrisorias distinciones. A los juristas, tanto a los profesores e investigadores, como a los prácticos y a los magistrados, les gusta ser reconocidos y consultados. Ninguno de nosotros está vacunado contra este tipo de virus que perdura en estado endémico en aquéllos en los que la perspectiva de prestigio reemplaza al afán de lucro.

${ }^{27}$ Detalles en mi estudio «Droit et Societé: du constat à la construction d'un champ commun», en Droit et Société, 20/21, 1992: 17-38. Cf. también: «Du jeu fini au jeu ouvert. Reflexions additionnelles sur le Droit postmoderne», en Derecho y sociedad, 17-18, 1991: 38-55; retomado en Le jeu: un paradigme pour le droit, bajo la dirección de F. Ost y M. Van de Kerchove, París. L.G.D.J., 1992 (col. «Droit et Société», vol. 2), pág. 111-131.

${ }^{28}$ Cfr. «Rossinante et le cheval de Troie», op. cit. 
Una de las tentaciones más importantes en este final de siglo consiste en buscar «situarse» en la carrera de Europa. Tenemos necesidad de expertos, y los tecnócratas se hacen gustosamente eurócratas. Los «buenos» profesores de Derecho comunitario pasan más tiempo en Bruselas que en su Facultad. Algunos prácticos avispados se organizan para tener una representación a las puertas del Tribunal de Luxemburgo y del de Estrasburgo. Saben que numerosas decisiones se preparan o se prepararán en sus despachos, en esta Europa jurídica que busca todavía abrirse caminos, inventar pistas.

Lo que es posible para los profesores y los prácticos no es siempre posible, sin embargo, para los magistrados. Una manera que tienen estos últimos de hacer valer sus méritos consiste en la proclamación de su independencia. Paradójicamente esto se traduce a menudo en lo que se denomina una «politización» de los jueces ${ }^{29}$. En el momento de la edición francesa de este libro éramos nuevos ricos; hasta 1975, momento en el que el joven y rebelde Sindicato de la Magistratura lanzaba sus críticas ante un gobierno de derechas. 1981 ha traído la izquierda al poder. De la noche a la mañana, los dirigentes de este Sindicato se encontraron con las riendas del Gobierno, en las Cancillerías, a la cabeza en los puestos estratégicos del poder judicial, y especialmente en la formación de los magistrados. Era la mejor manera de llevar a la práctica sus críticas. ¿Qué resultó de todo esto? Probablemente el porvenir retendrá, junto a algunas transformaciones no sin interés (como la entrada oficial de las ciencias sociales en la Escuela de la Magistratura), fundamentalmente un cierto estancamiento, una pérdida de sentido crítico, mucho entusiasmo reformador truncado ${ }^{30}$.

Al mismo tiempo, la investigación científica francesa se transforma. El departamento de Ciencias humanas y sociales es completamente reformado en 1991. La sección de ciencias jurídicas, separada desde hacía poco de la de ciencias políticas, es suprimida. Los investigadores juristas son reagrupados con los sociólogos en una sección común denominada «Sociología. Normas y reglas». El enfrentamiento parece inevitable entre los juristas -entre los cuales los elegidos para las comisiones del C.N.R.S. son mayoritariamente universitarios

${ }^{29}$ Se encontrará material para la reflexión en la obra de Alain Bancaud, La haute-magistrature judiciaire entre politique et sacerdoce, L.G.D.J., París, 1993.

${ }^{30}$ «La Cancillería parece haber renunciado a una verdadera reforma de las estructuras», declaraba por ejemplo Mme Delmas-Marty a propósito de la reforma del proceso penal emprendido en Francia, territorio neurálgico donde lo haya (Le Monde, 221/11/1991, pág. 13). Cfr. también la reciente tesis de Anne Devillé sobre dos décadas de acción del Sindicato de la Magistratura (Louvain-la-Neuve, 1992). 
surgidos de las Facultades que no son consideradas «de izquierdas»- y los sociólogos -doblemente desconfiados respecto a los primeros, a los que consideran como juristas impenitentes y políticamente de derechas. Es precisamente por la personalidad del presidente de la comisión (respetada por los dos partidos) y por la cercanía de las elecciones de marzo de 1993 (consideradas como propicias para una transformación radical) por lo que no se hará saltar el polvorín.

Lo menos que puede decirse es que, en estas condiciones, la coyuntura se presenta poco favorable para una reflexión intensa sobre las relaciones de los juristas y de su sociedad.

Hay que añadir a todo esto el otro canto de las sirenas, que constituye la llamada de los massmedia. La necesidad de sensacionalismo es una de las claves del éxito para el índice de audiencia: relación detallada de la audiencia que posee cada cadena televisiva o de radiodifusión. De este resultado depende el volumen de publicidad que le será confiado. Así, será trabajo de los periodistas abordar lo espectacular a cualquier precio. Muchos jueces, al ser interrogados sobre «casos» sensacionalistas que tienen a su cargo, no saben resistirse al atractivo de un micrófono o de una cámara; las indiscreciones circulan; corrupción política, delitos de sangre, lucha contra la droga, hacen de estos oscuros magistrados verdaderos sheriffs. Sus palabras son grabadas; ellos no siempre respetan su deber de reserva; en el «montaje» de las grabaciones, se cortan sus discursos para hacerlos compatibles con el precio del minuto en antena; y he aquí a los inculpados, los «presuntos culpables» -a veces hasta simples testigos-, juzgados incluso antes de que su caso haya sido seriamente objeto de un examen judicial.

Desaparecen así los últimos grandes sacerdotes; la aparición del juez en la pantalla descubre simples seres humanos atrapados como cualquiera por periodistas experimentados en este juego. No hemos salido todavía de esta contradicción: si se luchó mucho por ver desaparecer una justicia de clase, no era ciertamente para verla reemplazada por linchamientos populares.

Como anunciaba durante una audiencia solemne el Primer Presidente del Tribunal de Casación, no es fácil ser juzgado por los tiempos que corren ${ }^{31}$. Hace falta recordar la frase de Balzac: «La desconfianza en la magistratura y el menosprecio hacia los jueces, son los primeros pasos hacia una disolución de la sociedad».

Más grave: al mismo tiempo que, por el sendero trazado por los massmedia es arrojado el descrédito sobre «la justicia» en su conjunto, desaparecen los últimos bastiones de los valores de nuestra sociedad.

${ }^{31}$ Citada en Le monde, 16/1/93, pág. 15. 
En el momento en el que los que son los guardianes tradicionales de los valores de la justicia son ampliamente desacreditados, aparecen casos no aislados de malversación en el cuerpo médico que arrojan sospechas sobre el conjunto del cuerpo. La sociedad colocaba a los médicos por encima de cualquier acuerdo innoble. Un caso como el de la «sangre contaminada», que ha conmovido a toda la población de Francia e incluso a la de más allá de sus fronteras, no puede pasar sin empañar esta imagen.

Cuando amenaza la tempestad todos se ponen a cubierto: otras sirenas susurran el tranquilizante canto del repliegue corporativista. Es, en efecto, al corporativismo -al menos mientras que los motivos políticos no sean claramente expresados- al que atribuimos ciertas reacciones de juristas contra las reformas que otros presentan como progresistas.

Se llega así a la insurrección de los jueces de instrucción que Francia sufrió a comienzos del año 1993. ¿Cómo tantos magistrados de base han podido olvidar tan radicalmente el intocable principio de separación de poderes, hasta el punto de rechazar la aplicación de una legislación, democráticamente votada, que modificaba el proceso de instrucción, volviéndolo menos inquisitorio, más acusatorio? Nos quedamos desconcertados, ciertamente consternados con el tenor de sus quejas ${ }^{32}$. Los partidos de derechas transforman el caso en trampolín electoral y prometen la reforma en caso de victoria, se duda sobre el calificativo más apropiado.

El más puro corporativismo renace, sin embargo, con toda evidencia. Los profesores de Derecho que, tras los sucesos de mayo del 68, habían abandonado la toga, la volvieron a tomar casi unánimemente. Hasta en las nuevas Facultades de Derecho, forjándose una tradición, se introdujo -salvo en muy raras excepciones- esta costumbre. Algunos de los que en sus tiempos formaron el movimiento francés Critique du droit no se escaparon a la regla: algunos de ellos riéndose incluso de buena gana. Otros no... Todo esto parecería anecdótico si el hecho no hubiera coincidido con el retorno del mandarinato.

\section{B) El desconcierto de los juristas}

El mayor signo de desconcierto puede ser el no saber dónde situar al propio desconcierto. Después de lo dicho, llegaremos incluso a preguntarnos si existe. Pero si uno no quiere obnubilarse con el párrafo precedente, testigo de una perfecta auto-satisfacción, habrá que convenir que la confusión es latente. ¿Qué perspectivas se ofrecen a la sociedad para mejorar su regulación? ¿Qué medios se ofrecen

${ }^{32}$ Cfr. por ejemplo, Le Monde, 15/1/93, pág. 15. 
a los juristas para cumplir su tarea en el seno de la sociedad? ¿Está el cara a cara condenado a eternizarse?

Volvamos las miradas hacia la jurisprudencia, de la que Robert Mandrou, recordemos ${ }^{33}$, decía que reflejaba la estructura mental de los jueces -extrapolemos: de los juristas. ¿Qué nuevas líneas maestras podemos percibir? Vista la importancia que han adquirido (incluso en el seno de las jurisprudencias nacionales), serán los Tribunales europeos los que deberán ser interrogados ${ }^{34}$.

La unificación debe hacerse. ¿Será una integración jurídica? ¿Será una armonización de las legislaciones? El Tribunal de las Comunidades Europeas se inclina por la primera solución; más prudente, el Tribunal de Derechos Humanos intenta la segunda vía. ¿Pero qué racionalidad para esta unificación?

¿La racionalidad económica? El Tribunal de las Comunidades Europeas funciona evidentemente con ella. La economía es el motor de la C.E.E. y los jueces del Tribunal de Luxemburgo, europeos convencidos, piensan que Europa se hará por el bolsillo. La razón económica canta como una sirena en nuestros oídos; en su nombre deberíamos, sin dudarlo, volver a un Derecho fabricado completamente en nombre de esta razón, y que vendría a suplantar a aquel otro que no se dirigiera a realizar una comunidad de naciones en el marco de una economía neo-liberal globalizada. Sin embargo, los estudios sociológicos nos enseñan que, si hace falta encontrar un relevo al hegemónico poder de «dictar el Derecho» que corresponde al Estado-nación, no es ciertamente para atribuir este poder en su totalidad a un super-Estado-nación, corriendo permanentemente el riesgo de que se constituya como conjunto de las Comunidades Europeas.

Sin embargo el Tribunal de Estrasburgo se refiere siempre a una razón simbólica. No para de repetir la cantinela -retomada al unísono por el Tribunal de Luxemburgo- de los derechos humanos y de la democracia. Tiene sin duda mucha razón, mucha razón de no cansarse de repetirlo y mucha razón, igualmente, de hacer respetar en este santo sacramento el símbolo de la Europa unida. ¿Pero es suficiente repetir las letanías para conjurar a la suerte? Dicho de otra forma, si no queremos que estas invocaciones queden como simples rezos, hace falta que sustituyamos las oraciones por una construcción jurídica creíble, susceptible de suministrar a nuestros Derechos fundamentos

${ }^{33}$ Cfr. supra, Conclusión.

${ }^{34}$ No se trata evidentemente de rehacer aquí una demostración cuyos elementos se encuentran en los tratados de Derecho comunitario y una síntesis en mi pequeño libro sobre el pensamiento jurídico europeo, op.cit. No se podía sin embargo no volver, al final del artículo, sobre la relación entre la Europa naciente y el desconcierto de los juristas, apenas evocada más arriba y en otro contexto. 
serios y prácticos.

La contradicción interna -que conlleva, a la larga, el riesgo de conducir a callejones sin salida las intervenciones más valientes fundadas en el respeto de los derechos humanos y de la democracia- reside en el hecho de que estos principios son siempre enunciados en el marco de las «naciones», mientras que es precisamente el concepto tradicional de nación el que se cuestiona. La mayor incongruencia se encuentra en que la instancia suprema adquiere su nombre precisamente de esa palabra: el problema fundamental de las Naciones Unidas es, para empezar, que su referente es la nación.

En realidad, hay que resignarse a terminar constatando la ausencia de una razón jurídica que gobierne el Derecho contemporáneo; algo que explica en parte el desconcierto de los juristas contemporáneos. En otros términos, debemos reconocer, nosotros, juristas diferentes, que no hemos encontrado todavía en el Derecho contemporáneo una razón que no sea ni orden, ni paz. A nosotros nos corresponde inventarla. Eso no se consigue con una inspiración repentina, sino con un largo, paciente y a menudo sombrío trabajo sobre el terreno y en el despacho. Numerosos sociólogos juristas están trabajando. No tienen la exclusiva. Más de un filósofo, más de un teórico del Derecho se ha puesto a la búsqueda de un nuevo equilibrio mental. Aquellos historiadores que no han desaparecido en la tormenta interrogan al pasado con vistas a comprender mejor el presente. ¡Cuántos doctores, cualquiera que sea su especialidad y su lugar de práctica (Facultad, Palacio de justicia, Administración, sector privado), están dispuestos a unir sus esfuerzos en un proyecto interdisciplinar que pondría término, por fin, a este largo cara a cara de los juristas y la sociedad! Para que nuestro siglo no termine como las sirenas de Ulises (tan bellas hasta la cintura y dotadas de una voz tan hermosa... pero que, como recuerdan Horacio, Virgilio y Séneca, desinunt in piscem ${ }^{35}$ ) acabemos con las disputas entre escuelas y unamos nuestros esfuerzos en la búsqueda de un Derecho para el mañana. dolor»

«Hay algo especialmente mórbido en la simpatía que tiene nuestra época por el

Oscar Wilde, Retrato de Dorian Gray, Cap.3. (Trad. Isabel Lifante Vidal y Victoria Roca Pérez)

${ }^{35}$ Horacio, de arte poetica, 4; virgilio, AEneis, 10, 211; Seneca, Epistulae ad Lucilium, 92, 10; $66,43$. 